\title{
Clinical outcome comparison of immediate blanket treatment versus a delayed pathogen-based treatment protocol for clinical mastitis in a New York dairy herd
}

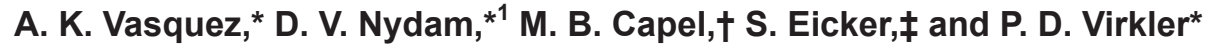 \\ *Department of Population Medicine and Diagnostic Sciences, College of Veterinary Medicine, Cornell University, Ithaca, NY 14853 \\ †Perry Veterinary Clinic, Perry, NY 14530 \\ ¥Valley Agricultural Software, King Ferry, NY 13081
}

\begin{abstract}
The purpose was to compare immediate intramammary antimicrobial treatment of all cases of clinical mastitis with a selective treatment protocol based on 24 -h culture results. The study was conducted at a 3,500cow commercial farm in New York. Using a randomized design, mild to moderate clinical mastitis cases were assigned to either the blanket therapy or pathogen-based therapy group. Cows in the blanket therapy group received immediate on-label intramammary treatment with ceftiofur hydrochloride for $5 \mathrm{~d}$. Upon receipt of $24 \mathrm{~h}$ culture results, cows in the pathogen-based group followed a protocol automatically assigned via Dairy Comp 305 (Valley Agricultural Software, Tulare, CA): Staphylococcus spp., Streptococcus spp., or Enterococcus spp. were administered on-label intramammary treatment with cephapirin sodium for $1 \mathrm{~d}$. Others, including cows with no-growth or gram-negative results, received no treatment. A total of 725 cases of clinical mastitis were observed; 114 cows were not enrolled due to severity. An additional 122 cases did not meet inclusion criteria. Distribution of treatments for the 489 qualifying events was equal between groups (pathogen-based, $\mathrm{n}$ $=246$; blanket, $\mathrm{n}=243$ ). The proportions of cases assigned to the blanket and pathogen-based groups that received intramammary therapy were 100 and 32\%, respectively. No significant differences existed between blanket therapy and pathogen-based therapy in days to clinical cure; means were 4.8 and $4.5 \mathrm{~d}$, respectively. The difference in post-event milk production between groups was not statistically significant (blanket therapy $=34.7 \mathrm{~kg}$; pathogen-based $=35.4 \mathrm{~kg}$ ). No differences were observed in test-day linear scores between groups; least squares means of linear scores was 4.3 for pathogen-based cows and 4.2 for blanket therapy cows. Odds
\end{abstract}

Received June 14, 2016.

Accepted December 7, 2016.

${ }^{1}$ Corresponding author: dvn2@cornell.edu of survival $30 \mathrm{~d}$ postenrollment was similar between groups (odds ratio of pathogen-based $=1.6 ; 95 \%$ confidence interval: $0.7-3.7$ ) as was odds of survival to 60 $\mathrm{d}$ (odds ratio $=1.4 ; 95 \%$ confidence interval: $0.7-2.6$ ). The one significant difference found for the effect of treatment was in hospital days; pathogen-based cows experienced, on average, 3 fewer days than blanket therapy cows. A majority (68.5\%) of moderate and mild clinical cases would not have been treated if all cows on this trial were enrolled in a pathogen-based protocol. The use of a strategic treatment protocol based on 24 -h postmastitis pathogen results has potential to efficiently reduce antimicrobial use.

Key words: clinical mastitis, cephapirin, ceftiofur, no treatment

\section{INTRODUCTION}

Clinical mastitis (CM) is defined by visible signs of inflammation in an affected mammary gland such as redness, swelling, pain, or heat, and alterations such as clots, flakes, discoloration, or abnormal consistency of secretions. Clinical mastitis has a high incidence on North American dairy farms, ranging from 20 to $51 \%$ of cows (Sargeant et al., 1998; Olde Riekerink et al., 2008). This disease can create severe economic losses due to discarded milk, reduced production, decreased conception, premature culling, transmission to other cattle, and treatment costs (Fetrow, 2000; Hertl et al., 2014). The current practice on many farms is treatment of all CM cases or "blanket treatment" with intramammary (IMM) antimicrobials. In a previous Wisconsin study, $80 \%$ of all antimicrobial drugs used on dairies were used for treatment or prevention of mastitis (Pol and Ruegg, 2007a). Problems attributed to the use of antimicrobials in animals include potential drug residues in the food supply, possible development of antimicrobial resistance, and monetary losses associated with treatment and discarded milk (Owens et al., 1997; Barton, 2000). 
A recent economic deterministic approach estimated financial losses for $\mathrm{CM}$ during the first $30 \mathrm{~d}$ of lactation at $\$ 444$ per case, accounting for diagnostics, antimicrobial costs, nonsalable milk, veterinary costs, milk and reproductive losses, and replacement costs (Rollin et al., 2015). Pathogen-specific treatment may be preferential in an economic model as it has the ability to decrease the use of antimicrobials, leading to reduced risks of residues and lower treatment and milk-discard costs (MacDonald et al., 2011; Schukken et al., 2011).

Targeted therapy of CM using on-farm culture results or other accurate diagnostic tools can replace the routine use of broad-spectrum antimicrobials, replacing the dated practice of treating without diagnosis (Hogeveen et al., 2011). Selective treatment of CM is defined as the use of antimicrobials only for cases that may benefit from them; outcomes regarding antimicrobial usage in specific pathogen groups have been studied in depth. Differences in cure rates between etiological bacteria may be attributed to the targeting of components of bacterial cell walls (Pyörälä et al., 1994). This proves difficult in gram-negative bacteria due to their complex additional lipopolysaccharide layer, likely reflected in the failure of efficacy for antimicrobial products in induced coliform mastitis trials (Lago et al., 2014). Where antimicrobials are not used, $85 \%$ spontaneous bacteriological cure rates for experimentally induced gram-negative Escherichia coli have been observed by d 7 (Leininger et al., 2003). Furthermore, 30\% or greater of $\mathrm{CM}$ cases exhibit culture-negative outcomes when sampled, for which the use of antimicrobials can be difficult to justify (Lago et al., 2011a; Oliveira and Ruegg, 2014).

Contrary to gram-negative CM, many IMM products are labeled for the treatment of gram-positive bacteria. Aggressive IMM treatment of clinical and subclinical cows infected with CNS and experimentally induced cases of environmental Streptococcus uberis, for example, is often successful with some cure rates exceeding 90\% (Hillerton and Kliem, 2002; Oliver et al., 2004). Alternatively, the spontaneous cure rate for CM caused by environmental Streptococcus spp. may exceed 50\%, but these cows can suffer frequent relapses (Morin et al., 1998).

Subsequent to the publication of studies analyzing "gram-specific" treatment response, farms gravitated toward a "treat or no-treat" system: gram-positive environmental pathogens were treated with IMM antimicrobials and gram-negative and no-growth culture cows remained untreated. No significant differences were seen in probability of bacteriological cure of a culture-based system versus blanket therapy when such a protocol was employed (Keefe et al., 2010). Likewise, Lago et al. (2011a,b) showed no significant differences between blanket treatment and selective treatment groups in $\mathrm{CM}$ recurrence, days to clinical cure, bacteriological cure risk, treatment failure risk, SCC, culling, or milk production when 24-h culture results were used to make treatment decisions on 8 commercial farms.

Antimicrobial products currently available for IMM use not only have varying label claims that include effectiveness against gram-negative organisms, but also have diverse durations of use, formulations, and withdrawal periods, making it difficult to determine whether a treat or no-treat regimen is beneficial. Cephapirin sodium, a first generation cephalosporin, was recently described as noninferior to ceftiofur hydrochloride, a third generation cephalosporin, when considering bacteriological cure of gram-positive etiologies and clinical cure of all CM cases (Schukken et al., 2013). Results of this study led to speculation of how cephapirin would perform in a treat or no-treat pathogen-based system, as treatment time would result in 3 less antimicrobial treatments and 4 less treatment days per cow as compared with the more widely used ceftiofur: a Wisconsin survey of 51 dairies found of the cows receiving only IMM treatment for CM, $74.9 \%$ received ceftiofur and $13.7 \%$ received cephapirin (Oliveira and Ruegg, 2014). Economic benefits could be realized with a reduction in treatment time, duration, and product cost. The current trial is not a comparison of 2 different antimicrobials. Our objective, rather, was to determine if a protocol based on culture results, specifically treating gram-positives with cephapirin, offered similar outcomes to treating all cows with ceftiofur. To compare, we investigated differences in days to clinical cure, milk production, linear score (LS), risk of culling post-CM event, and hospital days. Our hypothesis is that a pathogen-driven treatment protocol, as used in the current trial, may not only decrease the use of antimicrobials and protect aspects of public health, but also create economic benefits for the farm.

\section{MATERIALS AND METHODS}

\section{Study Animals}

Clinical mastitis cases were assessed for inclusion at a 3,500 Holstein cow commercial dairy in central New York between December 2014 and April 2015 under Institutional Animal Care and Use Committee approval. This farm was chosen due to its large herd size, a monthly incidence of 5 to $6 \% \mathrm{CM}$, availability of reliable health records, consultation opportunity with management and veterinarians, and access to microbiological diagnosis of milk samples within $24 \mathrm{~h}$ of collection. This farm used DHIA services, which included monthly SCC and milk weights. Health records included treatment, 
treatment pen moves, time to resolution of clinical signs, and culling data.

\section{Case Definition}

Each CM case was detected by trained on-farm employees by observing abnormalities in milk such as changes in consistency and color or udder signs including hard, swollen, or red quarters. Cows exhibiting severe symptoms such as depression, anorexia, dehydration, or fever received systemic antimicrobials and anti-inflammatories and were excluded from the study. Other exclusion criteria were treatment with antimicrobials or anti-inflammatories in the previous $15 \mathrm{~d}$ or impending sale of the animal. Multiple quarters and subsequent cases from an individual cow were included. A cow was not excluded if it had multiple cases of mastitis before enrollment.

\section{Sample Collection and Treatment Assignment}

Using sterile technique, a milk sample was collected from each affected quarter into a milk culture tube. The tube was labeled and promptly placed in a $5^{\circ} \mathrm{C}$ refrigerator. Severity, quarter, and date entering hospital were recorded in Dairy Comp 305 (DC305; Valley Agricultural Software, Tulare, CA). Culture results within $24 \mathrm{~h}$ of sample collection were achieved through the use of daily sample pick-up via the Quality Milk Production Services (QMPS) program at the Animal Health and Diagnostic Center in Ithaca, New York. The study was a randomized design with cows in the herd assigned by DC305 to either the blanket therapy group or the pathogen-based treatment group. If a cow was enrolled a successive time, the same treatment group was assigned.

\section{Microbiological Methods}

Standard culture technique was performed on all samples by QMPS employees according to National Mastitis Council guidelines for identification of aerobic organisms and Mycoplasma spp. (National Mastitis Council, 1999). Briefly, $0.01 \mathrm{~mL}$ of milk was streaked on trypticase soy agar containing 5\% sheep blood and $1 \%$ esculin (PML Microbiologicals, Mississauga, ON, Canada) and MacConkey's agar (Hardy Diagnostics, Santa Maria, CA) for identification of gram-negative organisms, and plates were incubated aerobically at $37^{\circ} \mathrm{C}$ for 18 to $24 \mathrm{~h}$. After observation of colony morphology and hemolytic patterns, isolates were examined further by means of $3 \%$ potassium hydroxide, Gram staining, catalase and oxidase testing, PathoDx Strep Grouping Latex tests (Thermo Fisher Scientific, Lenexa, KS), and additional biochemical and metabolic evaluations as needed. Mycoplasma spp. were identified using a dissection microscope after anaerobic incubation at $37^{\circ} \mathrm{C}$ for $7 \mathrm{~d}$ on Mycoplasma agar (Sigma-Aldrich LLC, St. Louis, MO).

Diagnosis and confirmation of IMM infection by culture of a single quarter milk sample was based on standard published definitions (Dohoo et al., 2011). Confirmation of etiologic cause was defined as the isolation of one or more colonies from 10 microliters of milk for all pathogens except for CNS. For CNS, 2 or more colonies isolated from the sample were needed to establish the presence of an infection. When 2 or more different bacterial pathogens were identified in the same sample, the result was classified as a mixed infection. If one nonpathogenic or $\geq 2$ dissimilar nonpathogenic colony types were present in low levels ( 1 to 5 colonies), the culture was defined as having no significant growth (i.e., the cow is unlikely to have an IMI). Contamination was defined as the isolation of 3 or more different colony types ( $>5$ colonies each) from the milk sample.

A cow in either treatment group with positive cultures for Prototheca spp., Mycoplasma spp., Staphylococcus aureus, or Streptococcus agalactiae was culled when its meat residue was no longer violative. This practice was standard herd policy before the start of the trial. Secondary IMM treatment after the eighth day of enrollment was allowed in cases that did not respond to the initial treatment. Any cow not following protocol was excluded from analysis. Each cow was followed until the end of its current lactation, the date it was culled, or $60 \mathrm{~d}$ postenrollment, whichever arrived first.

\section{Treatment Groups}

Blanket Therapy Group. In the blanket therapy (BT) group, immediately after enrollment, cows received 1 tube of ceftiofur hydrochloride into the affected quarter(s) (Spectramast LC; Zoetis, Florham Park, NJ). The treatment was repeated once every $24 \mathrm{~h}$ for $5 \mathrm{~d}$ according to label directions.

Pathogen-Based Treatment Group. In the pathogen-based (dPB) treatment group, direct upload of culture results to the on-farm computer was performed daily. Dairy Comp 305 automatically assigned the following treatment regimen based on pathogen: cows positive for CNS, Streptococcus group G, Streptococcus group C, Streptococcus dysgalactiae, Strep. uberis, or Enterococcus spp. were administered one IMM tube of cephapirin sodium (ToDAY; Boehringer Ingelheim, St. Joseph, MO) every $12 \mathrm{~h}$ for 2 treatments according to the label directions. A cow positive for any other organism or no growth on culture plates was assigned 
to no treatment. If 2 organisms were present or mastitis occurred in 2 quarters, the presence of CNS or Strep. spp. determined treatment in all CM quarters with cephapirin.

All CM cows remained in the treatment pen until milk withdrawal times were met and milk returned to normal visual appearance. Entrance and exit dates, as well as the date that clinical signs became absent, were recorded by trained on-farm personnel. Any cow that graduated to severe clinical signs exited the trial and was treated systemically according to veterinary recommendations.

\section{Treatment Outcomes}

Cows in the study were followed up for clinical days, posttreatment milk production, posttreatment LS, survival in the herd, and hospital days. The clinical days outcome was defined as the time to clinical cure and was calculated as the number of days from entrance into the treatment pen until milk, udder, and systemic abnormalities associated with CM were undetectable. Linear score is a transformation of SCC, calculated as $[\ln (\mathrm{SCC} / 100) / \ln (2)]+3$ (Ali and Shook, 1980). Posttreatment LS and milk production were obtained from test d 8 to $43 \mathrm{~d}$ post-CM event. The hospital days outcome was defined as the time in the treatment pen and was calculated as the number of days between entrance and exit into and from this pen. All values and dates were retrieved from farm management (clinical days), DHIA test-day records (LS and milk production), and DC305 (culling and hospital days).

\section{Data Analysis}

The effects of selected explanatory variables on posttreatment outcomes were analyzed using general linear models for continuous variables and binomial logistic regression models for dichotomous outcomes. Continuous outcomes included clinical days, posttreatment milk production, posttreatment LS, and hospital days. Dichotomous outcomes included retention in the herd $30 \mathrm{~d}$ postenrollment and retention in the herd 60 d postenrollment. Continuous explanatory variables included milk production and LS at previous DHIA test (8-43 d before the event). Explanatory categorical variables tested were mastitis event (1st, 2nd, or $>2$ nd), parity (1st, 2 nd, or $\geq 3$ rd), and DIM (0-100 DIM, 101-200 DIM, and >200 DIM). All analyses were performed in SAS version 9.4 (SAS Institute Inc., Cary, NC) using PROC GLM and PROC LOGISTIC. To select the best model, all possible confounding variables were subjected to bivariate analysis by means of chisquared, t-tests, or ANOVA tests using PROC FREQ,
PROC TTEST, PROC REG, or PROC ANOVA. Interactions of each variable with the main effect of treatment group were assessed in a similar manner and any terms with a $P$-value $<0.2$ were offered into the models. Each variable was then examined by manual backward stepwise elimination in the regression until all possible explanatory variables with $P<0.1$ were included. In many of the models, the treatment variable was forced $(P>0.1)$. We used least squares means and $\alpha=0.05$ to describe means and confidence intervals, respectively, unless otherwise noted. Additionally, basic graphing techniques were used to assess normality, homoscedasticity, and linearity of variables. Data transformations were performed and reported as necessary.

Six final models were established describing (1) the average number of clinical days, (2) postevent milk production, (3) post-event LS, (4) the odds of survival at $30 \mathrm{~d}$, (5) the odds of survival at $60 \mathrm{~d}$, and (6) the average number of hospital days. Not all included animals had complete LS or milk yield data as some cows experienced the event in early lactation with no prior test day or experienced the event late in lactation with no post-CM test day. Cows were excluded from clinical days or hospital days analyses if pen moves were incomplete in the records. An animal was not included in a model if it was missing a data point for a parameter offered the model; the number of animals with complete data for each analysis is indicated in each table.

\section{RESULTS}

\section{Descriptive Data}

A total of 725 cases of CM were observed. Of those, 489 cases were enrolled in the study. Distribution between groups was similar with $50 \%$ cows $(n=246 / 489)$ assigned to the dPB protocol and $50 \%$ of cows $(\mathrm{n}=$ $243 / 489)$ assigned to the BT group. Cows with severe mastitis, amounting to $16 \%(\mathrm{n}=114 / 725$; $\mathrm{dPB}, \mathrm{n}=62$; BT, $\mathrm{n}=52 ; P=0.33$, were not eligible for enrollment. Cows were excluded from analysis if they received the wrong treatment $(\mathrm{n}=24 ; \mathrm{dPB}, \mathrm{n}=14 ; \mathrm{BT} \mathrm{n}=10$, $P=0.68)$, treatment with an additional antimicrobial within $7 \mathrm{~d}$ of enrollment $(\mathrm{n}=57$; $\mathrm{dPB}, \mathrm{n}=35$; $\mathrm{BT} \mathrm{n}$ $=22, P=0.17)$, or an event entry error $(\mathrm{n}=4$; $\mathrm{dPB}$, $\mathrm{n}=1$; BT, $\mathrm{n}=3, P=0.35)$. Cows excluded due to Staph. aureus positive and Mycoplasma spp. positive cultures were $4 \%(\mathrm{n}=28 / 725$; dPB, $\mathrm{n}=15$; BT, $\mathrm{n}=$ $13, P=0.85)$ and $1 \%(\mathrm{n}=9 / 725 ; \mathrm{dPB}, \mathrm{n}=8$; $\mathrm{BT}, \mathrm{n}$ $=1, P=0.04)$, respectively. Of the 489 cases enrolled in the study, parity distribution was $19 \%(\mathrm{n}=93 / 489)$, $30 \%(\mathrm{n}=147 / 489)$, and $51 \%(\mathrm{n}=249 / 489)$ for $1 \mathrm{st}$, 2nd, and 3rd lactation and greater. The overall mean and median for DIM was $165 \mathrm{~d}$ and $151 \mathrm{~d}$, respectively. 
Table 1. Cow-level descriptors for each treatment group

\begin{tabular}{|c|c|c|c|c|c|c|}
\hline \multirow[b]{2}{*}{ Item } & \multicolumn{2}{|c|}{ Treatment group } & \multirow[b]{2}{*}{ Total } & \multirow[b]{2}{*}{ Overall } & \multirow[b]{2}{*}{$\%$ of group } & \multirow[b]{2}{*}{$P$-value ${ }^{1}$} \\
\hline & $\begin{array}{l}\text { Pathogen based } \\
\quad(\mathrm{n}=246)\end{array}$ & $\begin{array}{l}\text { Blanket therapy } \\
\quad(\mathrm{n}=243)\end{array}$ & & & & \\
\hline Parity, no. & & & & & & 0.39 \\
\hline 1 st & 48 & 45 & 93 & & & 0.82 \\
\hline 2nd & 67 & 80 & 147 & & & 0.20 \\
\hline$\geq 3 \mathrm{rd}$ & 131 & 118 & 249 & & & 0.32 \\
\hline \multicolumn{7}{|l|}{ DIM } \\
\hline Mean & 169 & 161 & & 165 & & 0.43 \\
\hline Median & 154 & 150 & & 151 & & \\
\hline Mastitis event, ${ }^{2}$ no. & & & & & & 0.04 \\
\hline 1st & 137 & 157 & 294 & & & 0.05 \\
\hline 2nd & 52 & 51 & 108 & & & $>0.99$ \\
\hline$>2$ nd & 57 & 35 & 92 & & & 0.02 \\
\hline Milk yield, ${ }^{3} \mathrm{~kg}$ & $\mathrm{n}=232$ & $\mathrm{n}=219$ & & $\mathrm{n}=451$ & & \\
\hline Mean & 35.0 & 34.0 & & 34.5 & & 0.90 \\
\hline Median & 35.5 & 33.2 & & 35.0 & & \\
\hline Linear score ${ }^{3}$ & $\mathrm{n}=231$ & $\mathrm{n}=216$ & & $\mathrm{n}=447$ & & \\
\hline Mean & 3.8 & 3.5 & & 3.6 & & 0.22 \\
\hline Median & 3.2 & 2.8 & & 3.0 & & \\
\hline \multicolumn{7}{|c|}{ Intramammary treatment, no. } \\
\hline Ceftiofur & 0 & 243 & & & 100 & \\
\hline No treatment & 167 & 0 & & & 68 & \\
\hline Cephapirin & 79 & 0 & & & 32 & \\
\hline
\end{tabular}

Sixty percent of cows $(n=294 / 489)$ were experiencing their first mastitis event of the current lactation; this number was greater in the $\mathrm{BT}$ group than the $\mathrm{dPB}$ group ( $\mathrm{dPB}, \mathrm{n}=137 ; \mathrm{BT}, \mathrm{n}=157 ; P=0.05)$. The relationship was reversed in those cows experiencing their $>2$ nd mastitis event $(\mathrm{dPB}, \mathrm{n}=57 ; \mathrm{BT}, \mathrm{n}=35 ; P$ $=0.02$ ). Distribution of these descriptors by treatment group can be seen in Table 1. The mean and median number of days between enrollment and retrieval of test day data was $23 \mathrm{~d}(\mathrm{SD}=10 \mathrm{~d})$ and $21 \mathrm{~d}$, respectively.

On a herd level, 70\% ( $\mathrm{n}=340 / 489)$ of cultures produced diagnostic bacterial growth. The most commonly isolated pathogens at $24 \mathrm{~h}$ postincubation were gram-negative bacilli $(34 \%$; $\mathrm{n}=164 / 489)$, followed by Streptococcus spp. $(32 \% ; \mathrm{n}=155 / 489)$ and CNS $(2 \%$; $\mathrm{n}=10 / 489$ ). At $48 \mathrm{~h}$ postincubation, gram-negative organisms were further defined: $23 \%$ of all CM etiologies were E. coli $(\mathrm{n}=113 / 489), 6 \%$ Klebsiella spp. (n $=30 / 489)$, and $1 \%$ Pasteurella $(\mathrm{n}=8 / 489)$. Among the gram-positive organisms, Strep. uberis was most commonly isolated $(14 \% ; \mathrm{n}=66 / 489)$ followed by $S$. dysgalactia $(13 \% ; \mathrm{n}=63 / 489)$, other Streptococcus spp. (4\%; $\mathrm{n}=21 / 489)$, and CNS $(2 \% ; \mathrm{n}=11 / 489)$. The remaining 48-h diagnoses (gram-positive bacilli, Enterococcus spp., Corynebacterium spp., Enterobacter spp.) each represented less than $1 \%$ of all $\mathrm{CM}$ cases. Distribution of $24 \mathrm{~h}$ culture results by treatment group are listed in Table 2.
Treatment assignment and pathogen diagnostics resulted in 79 of 246 cows in the dPB treatment group receiving cephapirin, leaving $68 \%$ of $\mathrm{CM}$ cases ( $\mathrm{n}=$ $167 / 246)$ in the dPB group not treated with IMM antimicrobials.

\section{Effect of Treatment Protocol}

Effect on Clinical Days. Cases were only eligible for clinical days analysis if they had a recorded date for when milk and udder signs returned to normal. Exactly $59 \mathrm{dPB}$ cows were lost to follow-up for clinical days analysis due to placement into a nonhospital pen during the first month of the trial. Full data existed for all variables in the model for $150 \mathrm{dPB}$ cows and $219 \mathrm{BT}$ cows. Mixed linear regression involved a log-transformation of the clinical days outcome to provide normality of the variance. The resulting model provided a numerically lower number of clinical days for the dPB group; however, this difference was not statistically significant (LSM for $\mathrm{dPB}$ group $=4.5 \mathrm{~d}, \mathrm{BT}=4.8 \mathrm{~d} ; P=0.12$ ). The results of the final regression model are shown in Table 3. The noticeable parameter in the model was milk production $(P=0.02)$, which indicated a decrease in clinical days as production increased. A trend was observed for clinical days to increase with increasing DIM and increasing parity categories. 
Table 2. Cow-level etiology of infection at detection ${ }^{1}$

\begin{tabular}{|c|c|c|c|c|c|}
\hline \multirow[b]{3}{*}{$24 \mathrm{~h}$ culture result } & \multicolumn{4}{|c|}{ Treatment group } & \multirow[b]{3}{*}{$P$-value ${ }^{2}$} \\
\hline & \multicolumn{2}{|c|}{$\begin{array}{l}\text { Pathogen based } \\
\quad(\mathrm{n}=246)\end{array}$} & \multicolumn{2}{|c|}{$\begin{array}{l}\text { Blanket therapy } \\
\quad(\mathrm{n}=243)\end{array}$} & \\
\hline & no. & $\%$ & no. & $\%$ & \\
\hline No growth & 65 & 26 & 51 & 21 & 0.28 \\
\hline No significant growth & 16 & 7 & 17 & 7 & 0.86 \\
\hline CNS & 4 & 2 & 6 & 3 & 0.54 \\
\hline Streptococcus spp. & 75 & 31 & 80 & 33 & 0.63 \\
\hline Gram-negative bacillus ${ }^{3}$ & 84 & 34 & 80 & 33 & 0.77 \\
\hline Yeast spp. & 1 & 0.4 & 5 & 2 & 0.12 \\
\hline Trueperella pyogenes & 1 & 0.4 & 2 & 0.8 & $>0.99$ \\
\hline Corynebacterium spp. & 0 & 0 & 2 & 0.8 & 0.25 \\
\hline
\end{tabular}

${ }^{1}$ Etiological classification is based on aerobic culture results performed by Quality Milk and Production Services.

${ }^{2} P$-values based on bivariate analysis (Fisher exact) of each etiology by treatment group.

${ }^{3}$ Postancillary testing, these organisms were further characterized as Escherichia coli, Klebsiella spp., Pasteurella, or Citrobacter spp. or remained gram-negative bacillus at 48-h reading.

Effect on Test-Day Milk. The average post-CM test-day milk for all cows with test-day data $(\mathrm{n}=440)$ was $34.5 \mathrm{~kg}$. Full data existed for $202 \mathrm{dPB}$ cows and 206 BT cows in the model. Although not statistically significant, the mixed linear regression model indicated $+0.7 \mathrm{~kg}$ of milk for the dPB group (LSM dPB $=35.4$ $\mathrm{kg}, \mathrm{BT}=34.7 \mathrm{~kg} ; P=0.48)$. As expected, pre-CM milk production had an effect on post-event milk production. Cows earlier in lactation (0-100 DIM), on average, produced $5 \mathrm{~kg}$ more milk than those later in their lactations ( $>200$ DIM; $P<0.0001)$. In this herd, parity was important with 1 st and 2 nd parities producing more milk than those $\geq 3$ rd parity $(+2.8 \mathrm{~kg} ; P=0.04$; $+2.2 \mathrm{~kg} ; P=0.04$, respectively).

Effect on Test-Day Linear Score. No statistically significant difference existed in LS post-CM between cows assigned to either treatment program; BT cows experienced a numerically lower LS than dPB cows (n $=200$ for BT, $\mathrm{n}=196$ for $\mathrm{dPB} ; \mathrm{LS}=4.2$ and 4.3 , respectively; $P=0.58)$. As expected, LS before CM event was an important variable; as pre-CM LS increased, post-CM LS increased $(P<0.0001)$. Two other parameters remained important in the model: parity and mastitis event. These effects can be seen in Table 4 .

Effect on Probability of Survival at $30 \mathrm{~d}$. A total of 451 observations were used in logistic analysis to model the probability of survival at $30 \mathrm{~d}$ postevent; $5 \%$ of $\mathrm{CM}$ cows with full data $(\mathrm{n}=23, \mathrm{BT}=14 / 226$; $\mathrm{dPB}=9 / 225)$ did not remain in the herd beyond this time point. No significant difference was detected in odds of survival $30 \mathrm{~d}$ post-CM event between the treatment groups [odds ratio of $\mathrm{dPB}\left(\mathbf{O R}_{\mathrm{dPB}}\right)=1.6,95 \%$

Table 3. Parameter estimates and statistics for fixed effects of a linear regression model evaluating $\log ($ clinical days $)^{1} ; \mathrm{n}=369$

\begin{tabular}{llcccc}
\hline Parameter & Description & Estimate & LSM CD $^{2}$ & SE & $P$-value \\
\hline Intercept & Pathogen-based & 1.90 & & 0.09 & $<0.0001$ \\
Treatment & Blanket therapy & Referent & 4.5 & 0.04 & 0.12 \\
& & -0.005 & & 0.002 & 0.02 \\
Milk production, $^{3} \mathrm{~kg}$ & $0-100$ & -0.11 & 4.4 & 0.05 & 0.04 \\
DIM $^{4}$ & $101-200$ & -0.08 & 4.5 & 0.05 & 0.08 \\
& $>200$ & Referent & 4.9 & & \\
Parity & 1 & -0.15 & 4.3 & 0.06 & 0.01 \\
& 2 & -0.07 & 4.6 & 0.04 & 0.10 \\
& $\geq 3$ & Referent & 5.0 & & \\
\hline
\end{tabular}

${ }^{1}$ Parameters evaluated for potential confounding included parity, DIM at the clinical mastitis (CM) event, previous occurrence of a clinical mastitis case in the present lactation, and linear score and milk production at test day previous to event.

${ }^{2}$ Least squares means for clinical days.

${ }^{3}$ On test d 8 to 43 before CM event.

${ }^{4}$ At time of $\mathrm{CM}$ event. 
Table 4. Parameter estimates and statistics for fixed effects of a linear regression model evaluating linear score (LS) on test day after clinical mastitis $(\mathrm{CM})$ event $(8-43 \mathrm{~d})^{1} ; \mathrm{n}=396$

\begin{tabular}{llccc}
\hline Parameter & Description & Estimate & SE & $P$-value \\
\hline Intercept & Pathogen-based & 0.21 & 0.38 & $<0.0001$ \\
Treatment & Blanket therapy & Referent & 0.21 & 0.58 \\
& 1 & -0.95 & 0.30 & 0.002 \\
Parity & 2 & -0.24 & 0.24 & 0.31 \\
& $\geq 3$ & Referent & & \\
& & 0.26 & 0.05 & $<0.0001$ \\
LS $^{2}$ & 1st case & -1.06 & 0.30 & $<0.0001$ \\
Mastitis event & \\
& 2nd case & -0.75 & 0.33 & 0.02 \\
& $>$ 2nd case & Referent & & \\
\hline
\end{tabular}

${ }^{1}$ Parameters evaluated for potential confounding included parity, DIM at $\mathrm{CM}$ event, previous occurrence of a $\mathrm{CM}$ case in the present lactation, and LS and milk production at test day previous to the event.

${ }^{2}$ On test $\mathrm{d} 8$ to 43 before the $\mathrm{CM}$ event.

${ }^{3}$ At time of the CM event.

CI: $0.7-3.7 ; P=0.31]$. The only variable that remained in the model was pre-CM milk production. The odds ratio (OR) of this effect was 1.05 (95\% CI: 1.02-1.26).

Effect on Probability of Survival at $60 \mathrm{~d}$. Similar to $30 \mathrm{~d}$ odds, no significant difference existed in odds of survival $60 \mathrm{~d}$ post-CM event between the treatment groups $\left(\mathrm{OR}_{\mathrm{dPB}}=1.4,95 \%\right.$ CI: $\left.0.7-2.6 ; P=0.29\right)$. Out of $451 \mathrm{CM}$ cows, $11 \%(\mathrm{n}=50, \mathrm{BT}=27 / 226, \mathrm{dPB}=$ $23 / 225$ ) were culled by $60 \mathrm{~d}$. Estimates that remained significant in the model were those describing milk production, parity, and mastitis event. Similar to the 30-d model, cows had increased odds of survival as milk production increased $\left(\mathrm{OR}_{\mathrm{dPB}}=1.09 ; 95 \%\right.$ CI: 1.02-1.17). Parities 1 and 2 had increased odds of survival over parity $\geq 3$, and as the number of mastitis events in the current lactation increased categorically, odds of survival decreased. The logistic regression model describing OR and confidence intervals is shown in Table 5.
Effect on Hospital Days. Hospital days data were recorded for $424 \mathrm{CM}$ cases, 184 in the dPB and 240 in the BT group; $57 \mathrm{dPB}$ cows were lost to followup for clinical days analysis due to placement into a nonhospital pen during the first month of the trial. The number of cows with full data that were included in the regression model was $388(\mathrm{dPB}=166, \mathrm{BT}=222)$. A linear regression model for hospital days was also log-transformed for normality of variance and is shown in Table 6. After transformation of the estimates, least squares means for hospital days were $5.8 \mathrm{~d}$ for the $\mathrm{dPB}$ group and $8.8 \mathrm{~d}$ for the BT; the BT group spent $3 \mathrm{ad}-$ ditional days in the hospital pen $(P<0.0001)$.

\section{DISCUSSION}

We found that using a pathogen-based treatment protocol compared with a blanket therapy protocol for mild to moderate CM resulted in no significant differences in days to clinical cure, postevent milk production, test-day LS, and survival to 30 and $60 \mathrm{~d}$. Our study did not provide a direct comparison between a first-generation cephalosporin, cephapirin, and a thirdgeneration cephalosporin, ceftiofur, as was done in the noninferiority comparison performed by Schukken et al. (2013). Instead, we described an overall comparison of 2 distinct protocols; assessments between antimicrobial products were not included and were not important to our objectives. Although no differences existed between treatment groups for many of the evaluated outcomes, we found an advantage to the use of a protocol that selectively treated $32 \%$ of cows with IMM cephapirin while not treating most others: a significant decrease in the average number of hospital days $(3 \mathrm{~d})$. No growth, no significant growth, and gram-negative bacillus together accounted for more than $60 \%$ of mild to moderate cases of $\mathrm{CM}$ in this trial, meeting the described pat-

Table 5. Logistic regression for survival to $60 \mathrm{~d}$ after clinical mastitis $(\mathrm{CM})$ event $^{1}$; $\mathrm{n}=451$

\begin{tabular}{llccccc}
\hline Parameter & Description & Estimate & SE & $P$-value & Odds ratio & $95 \%$ CI \\
\hline $\begin{array}{l}\text { Intercept } \\
\text { Treatment }\end{array}$ & Pathogen-based & -0.53 & 0.66 & 0.42 & & \\
& Blanket therapy & 0.33 & 0.31 & 0.29 & 1.4 & $0.7-2.6$ \\
Milk production, ${ }^{2} \mathrm{~kg}$ & & 0.08 & 0.03 & 0.01 & 1.09 & $1.02-1.17$ \\
Parity & 1 & 0.64 & 0.47 & 0.17 & 1.9 & $0.8-4.7$ \\
& 2 & 0.87 & 0.40 & 0.03 & 2.4 & $1.1-5.2$ \\
Mastitis event & $\geq 3$ & Referent & & & & \\
& 1 st & 0.98 & 0.38 & 0.01 & 2.7 & $1.3-5.6$ \\
& 2nd & 0.40 & 0.41 & 0.32 & 1.5 & $0.7-3.3$ \\
\hline
\end{tabular}

${ }^{1}$ Probability modeled was "alive" at $60 \mathrm{~d}$. Covariates evaluated for potential confounding included parity, DIM at $\mathrm{CM}$ event, previous occurrence of a $\mathrm{CM}$ case in the present lactation, and linear score and milk production at test day previous to the event.

${ }^{2}$ On test d 8 to 43 before CM event. 
Table 6. Parameter estimates and statistics for fixed effects of a linear regression model evaluating $\log ($ hospital days $)^{1} ; \mathrm{n}=388$

\begin{tabular}{llcccc}
\hline Parameter & Description & Estimate & LSM & SE & $P$-value \\
\hline Intercept & Pathogen-based & 2.38 & & 0.09 & $<0.0001$ \\
Treatment & Blanket & Referent & 8.8 & 0.04 & $<0.0001$ \\
Milk production, ${ }^{2} \mathrm{~kg}$ & & -0.005 & & 0.002 & 0.01 \\
\hline
\end{tabular}

${ }^{1}$ Parameters evaluated for potential confounding included parity, DIM at the clinical mastitis event, previous occurrence of a clinical mastitis $(\mathrm{CM})$ case in the present lactation, and linear score and milk production at the test day previous to the event.

${ }^{2}$ On test d 8 to 43 before the $\mathrm{CM}$ event.

terns in recent studies (Schukken et al., 2013; Oliveira and Ruegg, 2014).

Our average clinical days (4.7) and clinical days by group (4.8 and 4.5) are comparable to the respective nonsevere ceftiofur-treated $(4.5 \mathrm{~d}, \mathrm{n}=262)$ and cephapirin-treated cows $(4.9 \mathrm{~d}, \mathrm{n}=49)$ in a recent Wisconsin mastitis survey (Oliveira and Ruegg, 2014). Our result was less than the ceftiofur-treated cows in an earlier study performed by the same group (Pinzon-Sanchez and Ruegg, 2011). The authors expressed that the large value, 5.4 clinical days, was due to the administration of IMM antimicrobials until the complete resolution of clinical signs. Another study detected lower values than those found in the present study, at 2.7 and $3.2 \mathrm{~d}$ for blanket-treated cephapirin and selectively treated gram-positive cases, respectively (Lago et al., 2011a). Sixty-seven percent of CM cows treated with cephapirin and an equivalent percentage of oxytocin-only treated cows exhibited clinical cure by $4.5 \mathrm{~d}$ after treatment in a study by Guterbock et al. (1993). In the current study, $52 \%(\mathrm{n}=85 / 163)$ and $39 \%(\mathrm{n}=92 / 235)$ exhibited clinical cure by $4.5 \mathrm{~d}$ for $\mathrm{dPB}$ and BT therapies, respectively. The Schukken et al. (2013) study analyzed this outcome using a different method; the authors described noninferiority for overall clinical cure when comparing on-label IMM cephapirin versus $5 \mathrm{~d}$ IMM ceftiofur. The 2013 study described no absolute difference $(0 \%)$ when considering clinical observations at $\mathrm{d}$ 10 and 17 post-CM. Our risk difference for a clinical cure by d 4.5 was noted above as $13 \%$ between treatments and reflects observations performed at earlier time points. Despite deviations from our findings, all authors referenced concluded no statistical differences between treatment groups in days to clinical cure.

Several reasons influenced our choice of evaluating clinical cure as an index of outcome. While the "gold standard" approach in research studies to evaluate treatment efficacy is serial culture for bacteriological cure, many initial cultures can return negative results, limiting the ability to determine cure. Follow-up samples also may result in a different pathogen or contamination. Bacteriologic cure rates at 14 and $21 \mathrm{~d}$ in
CM cows treated with pirlimycin were not significantly different for cows with mastitis caused by susceptible or resistant bacteria, indicating that this index of cure may not always be valid (Hoe and Ruegg, 2005). An indirect assessment such as LS or SCC as well as simple assessment of resolution of clinical signs provides a reliable perception of treatment success (Lago et al., 2004; Bradley and Green, 2009; Bradley et al., 2012). In fact, most producers pursue a remission of clinical signs foremost over immediate elimination of the causative organism; when the owner is not actively engaged in milking, the decision-making process is based on evaluation of individual-cow milking performance and observations by the milking staff (Roberson, 2003; Pinzon-Sanchez and Ruegg, 2011). For these reasons, we measured the number of days to resolution of clinical signs. Resolution of clinical signs is a subjective measure and blinding in regards to treatment was not performed in this trial. However, producers and researchers were unaware of objective primary outcomes, including LS, culling, and milk production. We acknowledge that normal milk may not constitute elimination of the infection, and likewise, the clinical phase may extend beyond the time of bacteriological cure. These are disadvantages to the use of a clinical scoring system (Roberson, 2003). Bacteriological cure using serial cultures can provide an additional indicator of efficacy and could be pursued to quantify differences in response between protocols. Furthermore, bacteriological culture of postmastitis samples would be advantageous for determining the presence and comparison of new and chronic IMI between groups.

Previous and current research has established that differences in cure rates are associated with etiology, previous milk yield, previous SCC, previous occurrence of $\mathrm{CM}$, treatment duration, parity or lactation of the animal, and stage of lactation (Pinzon-Sanchez and Ruegg, 2011). As the decision to treat BT cows was independent of pathogen result (these cows were treated immediately), a valid comparison of the treatment groups did not include pathogen in the model for clinical days. At diagnosis of CM, milk samples were 
retrieved and cultures were performed for cows in both groups to ensure that randomization occurred without creating bias for individual etiologies, cows with contagious organisms were identified, and cows in the $\mathrm{dPB}$ group received their treatment assignment. Objectives did not include assessing the effect of culture results on treatment outcomes, but rather the effect of the selected protocols. Subsequent mastitis events at the quarter-level were not followed; this is a limitation of the current study. Analysis and interpretation of followup mastitis events between groups would be difficult to assess as an unequal distribution in the categories of mastitis event number at enrollment existed (Table 1 ). More cows experiencing their first case of mastitis were allocated to the BT group, whereas more animals experiencing their 3rd or greater event were allocated to the dPB group. Cows with previous cases of CM are less likely to respond to therapy; a previous study by Pinzon-Sanchez et al. (2010) including 143 cases of CM showed that cows treated in the current lactation for the first time were 11 times less likely to have a recurrence than those experiencing a previous case of CM. Also, an increase in mastitis events during a lactation can result in decreased milk production, increased LS, increased risk of culling, and an increase in hospital and clinical days, creating a bias away from the null when considering differences in outcomes between groups. In this trial, any contribution of selection bias creates more opportunity for the dPB cows to experience these negative outcomes. Variables listed in the Pinzon-Sanchez study, including mastitis event number, were initially included as potential confounders when constructing a model and no statistical differences between treatments were observed.

Milk production and LS post-CM event were not significantly different between treatment groups in the current study. Our results were consistent with 3 previous mastitis trials comparing blanket treated to selectively treated cows ("no growths" and coliform-positive cows did not receive antimicrobials). No significant differences in LS or milk production were detected between groups (Van Eenennaam et al., 1995; Roberson et al., 2004; Lago et al., 2011b). A fourth study depicted no significant differences in postevent LS or in milk production between first and third generation cephalosporin treatments (Schukken et al., 2013). Conversely, a study by Shim et al. (2004) reported a continued loss of production for cows that were not treated with antimicrobials; in comparison, treated animals suffered $1 / 3$ of the stated loss. Approximately $40 \%$ of the cows in the 2004 study were experiencing their second or greater case of mastitis and distribution of cases between treatment groups was not described. Additionally, the author recognized that the continued milk loss in CM cases may have resulted from persistent subclinical mastitis.

The current study found no significant differences between treatment groups when assessing survival in the herd to 30 and $60 \mathrm{~d}$. Similarly, Lago et al. (2011a) found no statistical differences in removal from herd within 21 d when assessing outcomes for blanket-treated cephapirin cows versus a protocol treating only gram-positive CM cows. A subsequent time-to-event analysis from the same data set concluded that days to culling between groups was similar (Lago et al., 2011b). Previous to both studies, a 1995 trial assessing 2 different IMM treatments versus nontreatment of $\mathrm{CM}$ resulted in no differences in removal from the herd, an outcome that was independent of etiology (Van Eenennaam et al., 1995). In our study, milk yield at test was the most important predictor for retention in the herd when assessing survival indices. This agreed with a recent study assessing risk factors associated with short-term post-treatment outcomes (Pinzon-Sanchez and Ruegg, 2011).

Approximately 60 untreated dPB cows were placed into a nonhospital pen at time of diagnosis, creating potential bias in the models for clinical and hospital days. These cows exited the hospital pen at day zero; time to resolution of clinical signs is difficult to determine. Despite omission of these cows from clinical and hospital day analysis, the mean number of hospital days for those cows included was significantly different between groups. The authors were aware of the possibility of a 3 -d difference in outcomes when the trial commenced. Drug labels designate that using an antibiotic with a 1-d treatment and 96-h milk withhold versus using an antibiotic with a 5-d treatment and 72-h milk withhold would result in a 3 -d difference. However, dPB cows had a delay in treatment by $24 \mathrm{~h}$, resulting in a projected difference of $2 \mathrm{~d}$. Also, we could not assume that ceftiofur-treated cows, cephapirin-treated cows $(16 \%$ of the 489 enrolled cows; $\mathrm{n}=79$ ), or untreated cows $(34 \% ; \mathrm{n}=167)$ would experience resolution of clinical signs before the withhold date. Cows with etiologies known to have a longer duration of clinical signs at this farm (E. coli, Klebsiella spp.) were not treated in the $\mathrm{dPB}$ protocol; it was anticipated that these cows would contribute a higher number of clinical days to this group. Additionally, clinical signs proceeded beyond the withhold date for $52 \%$ of cephapirin-treated cows with full data $(\mathrm{n}=38 / 73)$, which included a large percentage of Streptococcus spp. positive mastitis cases $(\mathrm{n}=36)$. Of all cows experiencing greater than 6 clinical days, $56 \%$ had Streptococcus spp. positive cultures $(\mathrm{n}=56 / 100)$. Of the cows in the dPB group, $33 \%$ (n $=54$ of 163 with full data) experienced unresolved clinical signs by $\mathrm{d} 6$. 
The 3-d difference in days out of the tank between the $\mathrm{BT}$ and the $\mathrm{dPB}$ groups is an important attribute when considering economics. Pinzon-Sanchez et al. (2011) performed a decision tree analysis on treatment strategies for mild and moderate first-case CM in early lactation and found that the most cost-effective strategy when implementing on-farm culture was to treat gram-positive pathogens for $2 \mathrm{~d}$ (one treatment per day) while permitting culture-negative and gram-negative results to "self-cure." The mentioned study did not investigate the economics of treating twice daily for $1 \mathrm{~d}$, which would involve the same costs for treatments and labor, but dependent upon withdrawal time of product used, may decrease costs associated with discarded milk. Regardless, when modeling for pathogen, probability of recurrence, and probability of cure, routine extended therapy ( $\geq 5 \mathrm{~d}$ ) was not economically optimal under any circumstance (Pinzon-Sanchez et al., 2011). Extended antimicrobial treatments, defined as greater than $3 \mathrm{~d}$ of IMM treatments with or without systemic antimicrobials or anti-inflammatories, did not result in outcome benefits (i.e., fewer follow up treatments, less milk production, less culling) in excess of treatment costs (Steeneveld et al., 2011).

Until recently, the effect of delaying CM treatment for $24 \mathrm{~h}$ to allow for culture was not well defined; the idea that use of a pathogen-based system produced undesirable outcomes as compared with implementation of immediate treatment was a valid consideration. However, several studies have addressed this question, particularly for the delayed treatment of gram-positive $\mathrm{CM}$ etiologies. Immediate versus delayed treatment of all CM cases producing growth on agar or delayed treatment of only gram-positives cases indicated no differences in survival indices (Wagner et al., 2007; Lago et al., 2011b), LS and milk production (Lago et al., 2011b), clinical and bacteriological cures (Lago et al., 2011a), or mastitis recurrence (Wagner et al., 2007; Lago et al., 2011b). Conversely, these cases tended to have shorter milk discard time while decreasing antimicrobial use (Lago et al., 2011a). The majority of the referenced studies include data from multiple dairies. The authors recognize that trials using more than one herd may provide additional data that includes or accounts for variation among herds; a weakness in the current study exists if this study population is not representative of an external population. Certainly one should not generalize the results of this study to dairy farms that are not like this one. Despite the use of one dairy, ad hoc power analysis produced confidence in our results: with a power of $90 \%$ and a Type I error rate of 0.05 , we were able to detect differences in clinical and hospital days of $1.2 \mathrm{~d}$ or more, a 0.2 or more $\mathrm{kg}$ difference in milk yield, OR of 1.2 or greater for 30 and $60 \mathrm{~d}$ sur- vival, and differences in LS of 0.22 or more. Although a large sample from one herd may affect external validity and generalizability to heterogeneous dairies, it likely increases the reliability of application of the results to similar dairy farms.

Resistance to antimicrobials may contribute to the similarities found between treatment groups in the current study. Previous research indicates that resistance to cephalosporins may be more prevalent in gram-negative versus gram-positive mastitis-causing pathogens. Ruegg et al. (2015) analyzed phenotypic profiles of gram-positive, mastitis-causing organisms and determined that whereas ceftiofur and cephapirin were the most commonly used IMM products in the enrolled herds, almost none of the pathogens were phenotypically resistant to those compounds. The latter study agreed with the results of a European trial performed by Thomas et al. (2015). Particularly, among CM isolates of Strep. uberis and Staph. aureus, resistance to $\beta$-lactam antibiotics was absent. For E. coli, there was an absence of resistance for ceftiofur and minimal resistance for cephalexin (Thomas et al., 2015). Alternatively, Srinivasan et al. (2007) and Erskine et al. (2002) found cephalosporin resistance in 15.5 and $25.5 \%$ of $E$. coli isolates from cows with mastitis, respectively. As over $20 \%$ of cows in the current trial were culturepositive for $E$. coli, ceftiofur-treated resistant isolates may have decreased any differences in outcomes that could be realized. Regardless, the objectives of this trial were to compare treatment protocols and the cow-level response for each protocol; despite any resistance in mastitis isolates, benefits to the use of blanket therapy in regards to the explored outcomes were not found. Additionally, herds that use systemic ceftiofur for the treatment of various health conditions are more likely to have cows with less susceptible fecal isolates of $E$. coli than those that did not report ceftiofur use (Tragesser et al., 2006), suggesting that on a herd level, reduction of antimicrobials can decrease the potential for development of resistance.

Protocols that practice judicious and targeted use of antimicrobials by rapid identification and diagnosis not only decrease the potential for development of antimicrobial resistance, but also address a concern with violative residues. The risk of a residue violation is directly associated with IMM antimicrobial use (McEwen et al., 1991). It has been reported that drugs used for the treatment of $\mathrm{CM}$ contribute the highest average daily dose per cow per year (DDD) at 2.0 followed by drugs used for dry cow therapy at 1.58. These numbers compare with doses for the treatment of other ailments such as foot rot (0.39 DDD), metritis (0.32 DDD), and respiratory illness (0.14 DDD). The mean overall density of ceftiofur use in the report was significantly 
greater than the density of use for other compounds labeled for IMM CM treatment (Pol and Ruegg, 2007b). In the current trial, the assignment and administration of an IMM cephalosporin product based on pathogen results apportioned the antimicrobial to less than $40 \%$ of nonsevere mastitis cases.

\section{CONCLUSIONS}

Many organisms that cause mastitis are successfully cleared by a cow's immune system - a shift in etiologies of current dairies to mostly gram-negatives or "no growths" rather than contagious or gram-positive organisms creates a large opportunity to reduce the use of antimicrobials. Greater than $65 \%$ of moderate and mild $\mathrm{CM}$ cases would not have been treated if all cows on this trial were enrolled in a pathogen-based protocol. This strategic method of treatment decreased milk withholding time by $3 \mathrm{~d}$ for those cows on a pathogen-based treatment protocol, with no significant differences in days to clinical cure, milk yield, and LS postmastitis event, nor additional odds of culling in the 2 mo following. If mastitis treatment decisions are based on scientific reasoning and data indices, economic returns and aspects of public health will be protected.

\section{ACKNOWLEDGMENTS}

We acknowledge the support of the employees and veterinarians of the farm participating in this study as well as the QMPS technicians and couriers for correspondence with the farm and culture of the samples. Partial financial support and provision of antimicrobials was provided by Boehringer Ingelheim Vetmedica Inc. (St. Joseph, MO).

\section{REFERENCES}

Ali, A. K. A., and G. E. Shook. 1980. An optimum transformation of somatic cell concentration in milk. J. Dairy Sci. 63:487-490.

Barton, M. D. 2000. Antibiotic use in animal feed and its impact on human health. Nutr. Res. Rev. 13:279-299.

Bradley, A., J. Breen, C. Hudson, and M. Green. 2012. Monitoring treatment outcomes: Understanding and managing expectations. Pages 301-308 in Udder Health and Communication. H. Hogeveen and T. J. G. M. Lam, ed. Wageningen Academic Publishers, Wageningen, the Netherlands.

Bradley, A. J., and M. J. Green. 2009. Factors affecting cure when treating bovine clinical mastitis with cephalosporin-based intramammary preparations. J. Dairy Sci. 92:1941-1953.

Dohoo, I. R., J. Smith, S. Andersen, D. F. Kelton, S. Godden, and Mastitis Research Workers' Conference. 2011. Diagnosing intramammary infections: Evaluation of definitions based on a single milk sample. J. Dairy Sci. 94:250-261.

Erskine, R. J., P. C. Barlett, J. L. VanLente, and C. R. Phipps. 2002. Efficacy of systemic ceftiofur as a therapy for severe clinical mastitis in dairy cows. J. Dairy Sci. 85:2571-2575.
Fetrow, J. 2000. Mastitis: An economic consideration. Pages 3-47 in Natl. Mastitis Counc. Reg. Mtg. Proc., Atlanta, GA. Natl. Mastitis Counc., Inc., Madison, WI.

Guterbock, W. M., A. L. Van Eenennaam, R. J. Anderson, I. A. Gardner, J. S. Cullor, and C. A. Holmberg. 1993. Efficacy of intramammary antibiotic therapy for treatment of clinical mastitis caused by environmental pathogens. J. Dairy Sci. 76:3437-3444.

Hertl, J. A., Y. Schukken, F. Welcome, L. Tauer, and Y. Gröhn. 2014. Effects of pathogen-specific clinical mastitis on probability of conception in Holstein dairy cows. J. Dairy Sci. 97:6942-6954.

Hillerton, J. E., and K. E. Kliem. 2002. Effective treatment of Streptococcus uberis clinical mastitis to minimize the use of antibiotics. J. Dairy Sci. 85:1009-1014.

Hoe, F. G. H., and P. L. Ruegg. 2005. Relationship between antimicrobial susceptibility of clinical mastitis pathogens and treatment outcome in cows. J. Am. Vet. Med. Assoc. 227:1461-1468.

Hogeveen, H., S. Pyorala, K. Persson-Waller, J. S. Hogan, T. J. G. M. Lam, S. P. Oliver, Y. H. Schukken, H. W. Barkema, and J. E. Hillerton. 2011. Current status and future challenges in mastitis research. Pages 36-48 in Natl. Mastitis Counc. Ann. Mtg. Proc., St. Pete Beach, FL. Natl. Mastitis Counc. Inc., Madison, WI.

Keefe, G., J. McCarron, K. MacDonald, and M. Cameron. 2010. The scientific bases for using on-farm culture systems. Page 141-148 in in Natl. Mastitis Counc. Reg. Mtg. Proc., Albuquerque, NM. Natl. Mastitis Counc. Inc., Madison, WI.

Lago, A., S. M. Godden, R. Bey, P. L. Ruegg, and K. Leslie. 2011a The selective treatment of clinical mastitis based on on-farm culture results: I. Effects on antibiotic use, milk withholding time, and short-term clinical and bacteriological outcomes. J. Dairy Sci. 94:4441-4456.

Lago, A., S. M. Godden, R. Bey, P. L. Ruegg, and K. Leslie. 2011b. The selective treatment of clinical mastitis based on on-farm culture results: II. Effects on lactation performance, including clinical mastitis recurrence, somatic cell count, milk production, and cow survival. J. Dairy Sci. 94:4457-4467.

Lago, A., S. M. Godden, and P. L. Ruegg. 2014. Treat or not treat? Etiology-based treatment decisions for clinical mastitis. Page 43 in in Natl. Mastitis Counc. Reg. Mtg. Proc., Ft. Worth, TX. Natl. Mastitis Counc. Inc., Madison, WI.

Lago, A., D. Rhoda, and N. B. Cook. 2004. Using DHIA recorded individual cow somatic cell counts to determine clinical mastitis treatment cure rates. Page 290-291 in in Natl. Mastitis Counc. Reg. Mtg. Proc., Charlotte, NC. Natl Mastitis Counc., Inc., Madison, WI

Leininger, D. J., J. R. Roberson, F. Elvinger, D. Ward, and R. M. Akers. 2003. Evaluation of frequent milkout for treatment of cows with experimentally induced Escherichia coli mastitis. J. Am. Vet. Med. Assoc. 222:63-66.

MacDonald, K., G. Keefe, J. Roy, K. Leslie, and I. Dohoo. 2011. Economic assessment of using a $3 \mathrm{M}$ petrifilm on-farm culture system for selective treatment of clinical mastitis. Pages 47-51 in International Symposium on Mastitis and Milk Quality, St. Louis, Missouri. National Mastitis Council, Madison, WI.

McEwen, S. A., W. D. Black, and A. H. Meek. 1991. Antibiotic residue prevention methods, farm management, and occurrence of antibiotic residues in milk. J. Dairy Sci. 74:2128-2137.

Morin, D. E., R. D. Shanks, and G. C. McCoy. 1998. Comparison of antibiotic administration in conjunction with supportive measures versus supportive measures alone for treatment of dairy cows with clinical mastitis. J. Am. Vet. Med. Assoc. 213:676-684.

National Mastitis Council. 1999. Laboratory Handbook on Bovine Mastitis. National Mastitis Council Inc., Madison, WI.

Olde Riekerink, R. G., H. W. Barkema, D. F. Kelton, and D. T. Scholl 2008. Incidence rate of clinical mastitis on Canadian dairy farms. J. Dairy Sci. 91:1366-1377.

Oliveira, L., and P. L. Ruegg. 2014. Treatments of clinical mastitis occurring in cows on 51 large dairy herds in Wisconsin. J. Dairy Sci. 97:5426-5436.

Oliver, S. P., B. E. Gillespie, S. J. Headrick, H. Moorehead, P. Lunn H. H. Dowlen, D. L. Johnson, K. C. Lamar, S. T. Chester, and W. M. Moseley. 2004. Efficacy of extended ceftiofur intramammary 
therapy for treatment of subclinical mastitis in lactating dairy cows. J. Dairy Sci. 87:2393-2400.

Owens, W. E., C. H. Ray, J. L. Watts, and R. R. Yancey. 1997. Comparison of success of antibiotic therapy during lactation and the results of antimicrobial susceptibility tests for bovine mastitis. J. Dairy Sci. 80:313-317.

Pinzon-Sanchez, C., V. E. Cabrera, and P. L. Ruegg. 2011. Decision tree analysis of treatment strategies for mild and moderate cases of clinical mastitis occurring in early lactation. J. Dairy Sci. 94:1873-1892.

Pinzon-Sanchez, C., C. Hulland, and P. L. Ruegg. 2010. Post treatment outcomes of clinical mastitis on commercial dairy farms. J. Dairy Sci. 93(E-Suppl. 1):79.

Pinzon-Sanchez, C., and P. L. Ruegg. 2011. Risk factors associated with short-term post-treatment outcomes of clinical mastitis. J. Dairy Sci. 94:3397-3410.

Pol, M., and P. L. Ruegg. 2007a. Relationship between antimicrobial drug usage and antimicrobial susceptibility of gram-positive mastitis pathogens. J. Dairy Sci. 90:262-273.

Pol, M., and P. L. Ruegg. 2007b. Treatment practices and quantification of antimicrobial drug usage in conventional and organic dairy farms in Wisconsin. J. Dairy Sci. 90:249-261.

Pyörälä, S., L. Kaartinen, H. Kack, and V. Rainio. 1994. Efficacy of two therapy regimens for treatment of experimentally induced Escherichia coli mastitis in cows. J. Dairy Sci. 77:453-461.

Roberson, J. R. 2003. Establishing treatment protocols for clinical mastitis. Vet. Clin. North Am. Food Anim. Pract. 19:223-234.

Roberson, J. R., L. D. Warnick, and G. Moore. 2004. Mild to moderate clinical mastitis: Efficacy of intramammary amoxicillin, frequent milk-out, a combined intramammary amoxicillin, and frequent milk-out treatment versus no treatment. J. Dairy Sci. 87:583-592.

Rollin, E., K. C. Dhuyvetter, and M. W. Overton. 2015. The cost of clinical mastitis in the first 30 days of lactation: An economic modeling tool. Prev. Vet. Med. 122:257-264.

Ruegg, P. L., L. Oliveira, W. Jin, and O. Okwumabua. 2015. Phenotypic antimicrobial susceptibility and occurrence of selected resistance genes in gram-positive mastitis pathogens isolated from Wisconsin dairy cows. J. Dairy Sci. 98:4521-4534.

Sargeant, J. M., H. M. Scott, K. E. Leslie, M. J. Ireland, and A. Bashiri. 1998. Clinical mastitis in dairy cattle in Ontario: Frequency of occurrence and bacteriological isolates. Can. Vet. J. 39:33-38.
Schukken, Y. H., G. J. Bennett, M. J. Zurakowski, H. L. Sharkey, B. J. Rauch, M. J. Thomas, B. Ceglowski, R. L. Saltman, N. Belomestnykh, and R. N. Zadoks. 2011. Randomized clinical trial to evaluate the efficacy of a 5-day ceftiofur hydrochloride intramammary treatment on nonsevere gram-negative clinical mastitis. J. Dairy Sci. 94:6203-6215.

Schukken, Y. H., M. J. Zurakowski, B. J. Rauch, B. Gross, L. L. Tikofsky, and F. L. Welcome. 2013. Noninferiority trial comparing a first-generation cephalosporin with a third-generation cephalosporin in the treatment of nonsevere clinical mastitis in dairy cows. J. Dairy Sci. 96:6763-6774.

Shim, E. H., R. D. Shanks, and D. E. Morin. 2004. Milk loss and treatment costs associated with two treatment protocols for clinical mastitis in dairy cows. J. Dairy Sci. 87:2702-2708.

Srinivasan, V., B. E. Gillespie, M. J. Lewis, L. T. Nguyen, S. I. Headrick, Y. H. Schukken, and S. P. Oliver. 2007. Phenotypic and genotypic antimicrobial resistance patterns of Escherichia coli isolated from dairy cows with mastitis. Vet. Microbiol. 124:319-328.

Steeneveld, W., T. van Werven, H. W. Barkema, and H. Hogeveen. 2011. Cow-specific treatment of clinical mastitis: An economic approach. J. Dairy Sci. 94:174-188.

Thomas, V., A. deJong, H. Moyaert, S. Simjee, F. Garch, I. Morrissey, H. Marion, and M. Valle. 2015. Antimicrobial susceptibility monitoring of mastitis pathogens isolated from acute cases of clinical mastitis in dairy cows across Europe: VetPath results. Int. J. Antimicrob. Agents 46:13-20.

Tragesser, L. A., T. E. Wittum, J. A. Funk, P. L. Winokur, and P. J. Rajala-Schultz. 2006. Association between ceftiofur use and isolation of Escherichia coli with reduced susceptibility to ceftriaxone from fecal samples of dairy cows. Am. J. Vet. Res. 67:1696-1700.

Van Eenennaam, A. L., I. A. Gardner, J. Holmes, L. Perani, R. J. Anderson, J. S. Cullor, and W. M. Guterbock. 1995. Financial analysis of alternative treatments for clinical mastitis associated with environmental pathogens. J. Dairy Sci. 78:2086-2095.

Wagner, S., R. Erskine, and R. Olde Riekerink. 2007. Outcomes of onfarm culture-based mastitis therapy. Pages 200-201 in Proc. 46th Annu. Mtg. Natl. Mastitis Counc., San Antonio, TX. National Mastitis Council, Madison, WI 